\title{
Numerical Analysis on the Influence of Thermal Effects on Oil Flow Characteristic in High-Pressure Air Injection (HPAI) Process
}

\author{
Hu Jia, Jin-Zhou Zhao, and Wan-Fen Pu \\ State Key Laboratory of Oil and Gas Reservoir Geology and Exploitation, Southwest Petroleum University, \\ Chengdu, China \\ Correspondence should be addressed to Hu Jia, tiger-jia@163.com
}

Received 24 June 2012; Revised 9 September 2012; Accepted 9 September 2012

Academic Editor: Ricardo Perera

Copyright (c) $2012 \mathrm{Hu}$ Jia et al. This is an open access article distributed under the Creative Commons Attribution License, which permits unrestricted use, distribution, and reproduction in any medium, provided the original work is properly cited.

\begin{abstract}
In previous laboratory study, we have shown the thermal behavior of Keke Ya light crude oil (Tarim oilfield, branch of CNPC) for high-pressure air injection (HPAI) application potential study. To clarify the influences of thermal effects on oil production, in this paper, we derived a mathematical model for calculating oil flow rate, which is based on the heat conduction property in porous media from the combustion tube experiment. Based on remarkably limited knowledge consisting of very global balance arguments and disregarding all the details of the mechanisms in the reaction zone, the local governing equations are formulated in a dimensionless form. We use finite difference method to solve this model and address the study by way of qualitative analysis. The time-space dimensionless oil flow rate $\left(q_{\mathrm{D}}\right)$ profiles are established for comprehensive studies on the oil flow rate characteristic affected by thermal effects. It also discusses how these findings will impact HPAI project performances, and several guidelines are suggested.
\end{abstract}

\section{Introduction}

Air injection in light oil reservoirs (HPAI, referred to as high-pressure air injection) has gained greater attention during the last decade [1-3]. HPAI projects have been steadily increasing in recent years, especially in light oil carbonate reservoirs in the USA [4]. However, some controversies still exist on recovery mechanisms, especially for thermal effects. Over the years, HPAI has been considered a simple fuel-gas flood, giving little credit to the thermal drive as a production mechanism [5], where the flue gases provide the main driving mechanism for oil production and the thermal effects have very little impact on the oil recovery mechanism. For instance, Sakthikumar et al. [6] simulated the HPAI process as an immiscible nitrogen flood, and Glandt et al. [7] modeled the process as an isothermal flue 
gas flood with a 10-component EOS model. It was expected that the isothermal predictions would represent a conservative estimate of the incremental oil production.

Montes et al. [5] suggested that this combustion front acts as a bulldozer (often called "bulldozing effect") to mobilize most of the oil immediately ahead of it that cannot be displaced by any of the other driving mechanisms present (i.e., flue gases, hot water/steam displacement, etc.). Although the presence of this front has been recognized for decades, its relevance to the air injection process has not always been interpreted properly [8]. The preexisting evidence from the Buffalo Red River Unit (BRRU) and South Buffalo Red River Unit (SBRRU) in the Buffalo field indicates that oil is actually burning and suggests that the combustion front is having a favorable impact on the production performance of the oil field $[8,9]$. In this sense, HPAI can be viewed as a combination of gas flooding and heavy-oil combustion (frontal displacement) [9].

In laboratory study aspect, Shokoya [10] conducted combustion tests to illustrate that the "extra" oil is due to thermal effects from the combustion front and the combustion front has the ability to mobilize the residual oil. We have demonstrated that Keke Ya light oil could autoignite at initial reservoir conditions in previous studies [11, 12]. However, with time gone, many people still keep conservative viewpoint about oil recovery contributed by thermal effects. For instance, Sarma and Das [13] expressed an uncertain viewpoint that thermal effects would be expected to contribute more to the oil production by way of oilviscosity reduction. The crucial reason is due to lack of qualitative theory studies. In the aspect of numerical study, de Zwart et al. [14] indicated that as to a commercial numerical model, in some instances, HPAI was modeled as an isothermal flue gas drive, employing an equation of state (EOS) methodology. This approach, however, neglects combustion and its effects on both displacement and sweep. Furthermore, the EOS approach cannot predict if, and when, oxygen breakthrough at producers occurs. Combustion can be included in a limited fashion in simulations at the expense of extra computational time and complexity. In the available literature, combustion is taken generally into account under quite simplified conditions. Establishing a theory model to qualitatively analyze the thermal effects on oil production is needed thus it can provide some guidelines to achieve high performance HPAI projects. However, oil recovery by combustion is a very complex process, and there are many aspects of it that are not yet completely understood [9].

For a combustion modeling study, some simplifications should be addressed first. Debenest et al. [15] used a simplified mathematical model to study the smouldering processes in porous media, while the dependence of the physical properties of the constituents on temperature and to represent oxidative chemical reactions by a single-step heterogeneous reaction on the surface of the solid grains were ignored. Similar scenario, owing to the complexity of the problem, is that various simplifications had to be used in this study. The main simplifications are to ignore the dependence with temperature of fluid capacities, conductivities, compressibility, and compositional effects. In other words, the influences of thermal effects on oil production are mainly caused by oil-viscosity reduction, which is similar to the heavy oil in situ combustion process with the main recovery mechanism by way of oil-viscosity reduction. Ren et al. [16] suggested that oil viscosity less than $10 \mathrm{mPa} \cdot \mathrm{s}$, at reservoir temperature, is desirable for application of HPAI. It is believed that the elevated reservoir temperature during HPAI process could reduce oil viscosity even to a lower value around $1.0 \mathrm{mPa} \cdot \mathrm{s}$, and when other conditions are in the same premise, thermal effects are bound to provide a favourable extra oil increment thus it should not be disregarded. Although all simplified simulations cannot provide full and detailed knowledge of all aspects of the process, it can be used to establish a typology of the regimes that prevail under various 
conditions and to assess the validity of the assumptions made in classical macroscopic descriptions [15]. This is of great practical interest in the prospect of tackling large-scale problems.

In this study, a simplified model is developed for predicting the influences of thermal effects on oil flow rate and based on the heat conduction model in combustion tube experiments [17]. Many of the existing literatures report the combustion tube simulations all are based on this classical model. For instance, in consideration of fuel concentration in oxygen-enriched in situ combustion, Rodriguez and Mamora $[18,19]$ developed a new analytical model of the combustion zone in combustion tube experiments. Jabbari et al. [20] modeled the toe-to-heel air injection process and the temperature distribution was analytically formulated and compared to the experimental data. But these models always are using analytical solutions.

The goals of this paper are to study the influences of thermal effects on oil flow characteristic by way of qualitative analysis. The rest of this paper is organized as follows. Section 2 describes the preliminary analysis and model derivation. Section 3 introduces the finite difference method and ascertains the main parameters for numerical calculation. Section 4 makes comprehensive theoretical analysis on how the thermal effects will impact oil production during HPAI process. Finally, what we get in our paper is summarized in Section 5, and future directions are proposed.

\section{Theoretical Model Descriptions}

Based on the feasibility of autoignition for Keke Ya light oil, the following model assumptions will be well founded. The physical model is based on the combustion tube model originally proposed in [17] and we briefly summarize this model first. Penberthy and Ramey developed an analytical heat model of movement of a burning front axially along a cylinder with heat loss through an annular insulation. A heat balance may be made for a differential element ahead of the burning front. It is well known that a stationary regime and a typical combustion front speed could exist in solid/gas combustion [15, 21, 22]. Hence, a moving coordinate system such that the burning front is always at the $x$-coordinate zero is used; correspondingly, the $x$-coordinate represents distance from the burning front. The model to describe the temperature profile ahead and behind the combustion front for combustion tube experiments is based on heat balance (conduction and convection) for a differential element in the combustion tube. The classical model is written by the following expression:

$$
\frac{k_{b}}{C_{f} \rho_{\mathrm{ma}}} \frac{\partial^{2} T}{\partial x^{2}}+\left(v_{b}-\frac{\rho_{g} C_{g}}{C_{f} \rho_{\mathrm{ma}}} u\right) \frac{\partial T}{\partial x}-\frac{2 U}{C_{f} \rho_{\mathrm{ma}} r_{t}}\left(T-T_{a}\right)=\frac{\partial T}{\partial t}
$$

The appropriate initial and boundary conditions are

$$
T(0, t)=T_{c}
$$




$$
\begin{gathered}
T(0, x)=0, \\
\lim _{x \rightarrow \infty} \frac{\partial T}{\partial x}(t, x)=0,
\end{gathered}
$$

where $k_{b}$ is the thermal conductivity, $\mathrm{kJ} / \mathrm{m} \cdot{ }^{\circ} \mathrm{C} ; \mathrm{C}_{f}$ is the specific heat of the matrix, $\mathrm{kJ} / \mathrm{kg} \cdot{ }^{\circ} \mathrm{C}$; $C_{g}$ is the specific heat of air, $\mathrm{kJ} / \mathrm{kg} \cdot{ }^{\circ} \mathrm{C} ; \rho_{\text {ma }}$ is the density of the matrix, $\mathrm{g} / \mathrm{cm}^{3} ; u$ is the superficial air velocity at burning front, $\mathrm{m}^{3} / \mathrm{hr} \cdot \mathrm{m}^{2} ; T$ is the temperature, ${ }^{\circ} \mathrm{C} ; T_{a}$ is the ambient temperature, ${ }^{\circ} \mathrm{C} ; T_{c}$ is the peak temperature, ${ }^{\circ} \mathrm{C} ; x$ is the distance from the burning front, $\mathrm{cm}$; $U$ is the overall heat conduction coefficient through the annular insulation, $\mathrm{kJ} / \mathrm{hr} \cdot \mathrm{m}^{2} \cdot{ }^{\circ} \mathrm{C} ; r_{t}$ is the radius of the combustion tube, $\mathrm{cm} ; t$ is time, hr; $v_{b}$ is the velocity of the burning front, $\mathrm{m} / \mathrm{hr}$.

It is noted that (2.2) and (2.4) specify that the initial temperature in the pack and the surrounding temperature are different.

Substituting

$$
\begin{gathered}
\alpha=\frac{k_{b}}{C_{f} \rho_{\mathrm{ma}}}, \\
\beta=v_{b}-\frac{\rho_{g} C_{g}}{\rho_{\mathrm{ma}} C_{f}} u, \\
\gamma=\frac{2 U}{\rho_{\mathrm{ma}} C_{f} r_{t}},
\end{gathered}
$$

(2.2) becomes

$$
\alpha \frac{\partial^{2} T}{\partial x^{2}}+\beta \frac{\partial T}{\partial x}-\gamma\left(T-T_{a}\right)=\frac{\partial T}{\partial t}
$$

The conceptual representation of air injection process along with the combustion tube (counterpart) is illustrated in Figure 1. Air injection process involves injection of high pressure air into a reservoir to promote in situ oil oxidation. Oxidation is a slow process in which $\mathrm{O}_{2}$ present in the injected high-pressure air reacts with hydrocarbons in the oil. When this happens, reservoir temperature in the vicinity of the air-oil contact rises and, eventually, oil autoignites resulting in the in situ generation of flue gases and steam [13, 23]. Reservoir oil will be mobilized towards producing wells through a combination of several complex mechanisms. Combustion is an exothermic process, which is due to the exothermic reaction between the fuel in the porous solid and oxidizer contained in the gas flowing through the solid [21]. In addition, the reservoir often creates better adiabatic conditions, and that can create a more favourable condition for heat conduction [24]. Hence, after oil autoignition, reservoir temperature profile can steadily move to a far distance, and the frontal oil properties will soon be affected. It seems matching with the interpretation of Figure 1 that the complex recovery mechanisms such as flue gas driven, oil swell, "stripping" of light volatiles, and reservoir repressurized, are only dominated in the vicinity of the injection well (zone, 1, 2, and 3 ) the unswept reservoir (zone 4) will receive steady thermal energy to reduce oil viscosity.

In this study, the indicated oil production contributed by thermal effects is based on oil physical viscosity reduction as mentioned in Introduction. For application of HPAI in light oil 


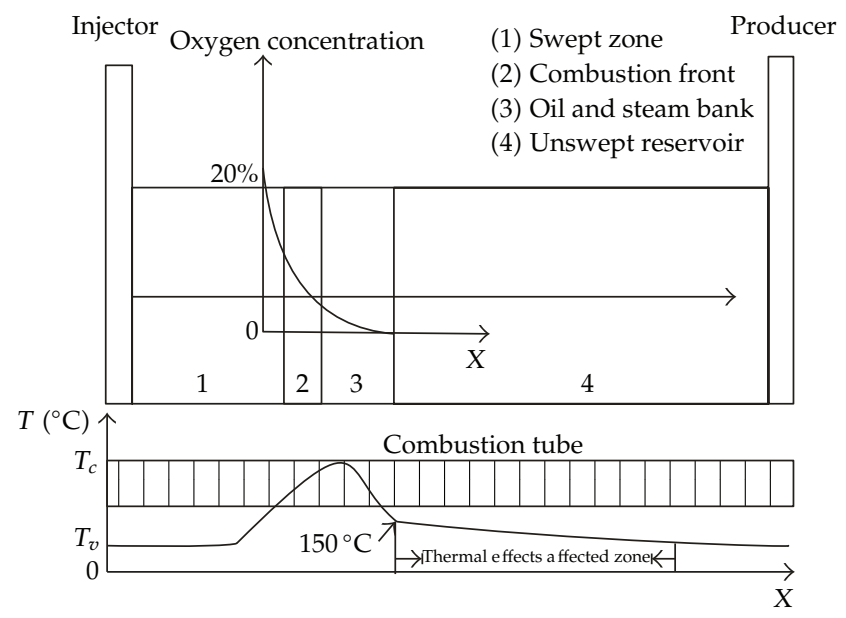

Figure 1: Compared diagrams of conceptual air injection process and combustion tube experiment.

reservoirs, low temperature oxidation (LTO) is the main concerned aspect [25]; in this stage, bond-scission reactions typically occur at temperature in the range of $150-350^{\circ} \mathrm{C}[26,27]$. Hence, crude oil will experience more complex chemical reactions and oil-viscosity reduction will not exist in LTO stage. Whereas crude oil often does not experience bond-scission reactions below $150^{\circ} \mathrm{C}$ [26], only simple physical phenomena of viscosity reduction will be exhibited. For the next discussion, we choose $150^{\circ} \mathrm{C}$ as the peak temperature for reducing oil viscosity and oil can be mobilized by thermal effects in the temperature decreasing profile. The legend of thermal effects affected zone in Figure 1 vividly shows that extra oil is expelled out below the upper limit temperature $\left(150^{\circ} \mathrm{C}\right)$ zone due to viscosity reduction. Correspondingly, the value of combustion front temperature $T_{C}$ described in Penberthy and Ramey's model is equal to upper limit temperature $\left(150^{\circ} \mathrm{C}\right)$.

\subsection{Physical Model and Assumptions}

We choose a long combustion tube as the basic physical model. The assumptions are listed as follows.

(1) The combustion tube is heterogeneous and prior saturated with oil only. The inlet and the outlet act as the injection well and produce well, respectively. Backpressure is employed as the reservoir pressure, while injection pressure keeps constant to make oil producing pressure drop in a constant value in whole process.

(2) The conceptual combustion tube is long enough and air injection rate is as low as possible so that premature gas breakthrough would not happen. Therefore, oil phase located at a far distance (unswept zone) ahead of peak temperature still displays single-phase porous flow and oil permeability is calculated by Darcy's law. It was assumed that the capillary pressure is zero. This is a reasonable assumption for crushed sands which generally have large pore sizes [28]. 
(3) As mentioned above (Section 2), the unswept reservoir will receive steady thermal energy to reduce oil viscosity and some other recovery mechanisms (i.e., oil swelling, reservoir repressurized, etc.) do not exist; it should be noted that oil phase located at the far distance is extracted out under the constant producing pressure gradient; in other words, it will exhibit the same pressure gradient below the upper limit temperature $\left(150^{\circ} \mathrm{C}\right)$ zone.

\subsection{Model Derivation}

We introduce here a basic solution in an extremely simple case, because it provides a guideline for the interpretation of more detailed simulation results. Most of the following is classical. In addition, the assumptions are not required for establishing the main global results. Hence, we remain here at a rather coarse level, which is sufficient for our present purpose. Complex recovery mechanisms take place in the travelling reaction zone, but we do not need to detail them at this stage. In the following section, we formulate the mathematical model and the physical conditions to which it corresponds.

Oil flow rate is based on Darcy's law and can be expressed as follows [20]:

$$
q=\frac{K_{\mathrm{o}} A}{\mu_{\mathrm{o}}}\left(\frac{\partial P}{\partial x} \pm \rho_{\mathrm{o}} g \sin \theta\right)
$$

where $q$ is the oil flow rate in $\mathrm{cm}^{3} / \mathrm{s}, K_{o}$ is the oil permeability in $\mu \mathrm{m}^{2}, \mathrm{~A}$ is the cross-sectional area of combustion tube available for flow in $\mathrm{cm}^{2}, \mu_{o}$ is the oil viscosity in $\mathrm{mPa} \cdot \mathrm{s}, \rho_{o}$ is the oil density in $\mathrm{kg} / \mathrm{m}^{3}, g$ is acceleration due to gravity in $10^{7} \mathrm{~m} / \mathrm{s}^{2}, P$ is pressure in a certain point in combustion tube in $10^{5} \mathrm{~Pa}, x$ is the distance from burning front in $\mathrm{cm} . \theta$ represents the reservoir dip angle in ${ }^{\circ}$; " \pm " indicates that the gravity can be acted as driving force and resistance for oil flow, respectively.

When the producing pressure gradient keeps constant, (2.7) becomes

$$
q=\frac{K_{\mathrm{o}} A}{\mu_{\mathrm{o}}}\left(G \pm \rho_{\mathrm{o}} g \sin \theta\right)
$$

where $G$ is the producing pressure gradient across the combustion tube in $10^{5} \mathrm{~Pa} / \mathrm{cm}$ and is calculated through the expression $G=\Delta P / L, L$ is the combustion tube length in $\mathrm{cm}$, and $\Delta P$ is the producing pressure difference across the combustion tube in $10^{5} \mathrm{~Pa}$.

If the reservoir dip is equal to zero, $(2.8)$ is written as

$$
q=\frac{K_{\mathrm{o}} A G}{\mu_{\mathrm{o}}}
$$

The regressed oil-viscosity temperature curve usually can be written by

$$
\mu_{\mathrm{o}}=\lambda \cdot e^{\omega T},
$$

where $\lambda$ and $\omega$ are correlation coefficients in the regressed equations in $\mathrm{mPa} \cdot \mathrm{s}$ and ${ }^{\circ} \mathrm{C} . T$ is temperature in ${ }^{\circ} \mathrm{C}$. Before oil autoignition, oil flow is at reservoir temperature $T_{v}$, implying 
that the constant oil viscosity $\mu_{v}$ at $T_{v}$ can provide a constant oil flow rate $q_{v}$ which can be written as

$$
q_{v}=\frac{K_{\mathrm{o}} A G}{\mu_{v}}
$$

Defining the parameter $\Theta=K_{o} A G / \lambda,(2.11)$ becomes

$$
q=\frac{\Theta}{e^{\omega T}}
$$

From (2.12), temperature is given as follows

$$
T=\frac{\ln (\Theta / q)}{\omega}
$$

The ambient temperature $T_{a}$ in the aforementioned model is equal to the initial reservoir temperature $T_{v}$. After substitution and rearrangement, (2.6) becomes

$$
\left(\frac{-\alpha}{q} \frac{\partial^{2} q}{\partial x^{2}}+\frac{\alpha}{q^{2}}\left(\frac{\partial q}{\partial x}\right)^{2}\right)-\frac{\beta}{q} \frac{\partial q}{\partial x}-\gamma\left(\ln \frac{q v}{q}\right)=-\frac{1}{q} \frac{\partial q}{\partial t}
$$

In combination with (2.2)-(2.4) and (2.13), we rearrange the initial and boundary conditions.

The initial condition is written as follows:

$$
q(0, x)=q_{v}
$$

The boundary conditions are

$$
\begin{gathered}
q(t, 0)=q_{c} \\
\lim _{x \rightarrow \infty} \frac{\partial q}{\partial x}(t, x)=0 .
\end{gathered}
$$

When burning front formed, the internal boundary in the moving $x$-coordinate always can provide a maximum oil flow rate of $q_{c}$ at upper limit temperature $\left(T_{C}\right)$. It should be noted that oil viscosity becomes $\mu_{c}$, correspondingly. whereas in the external boundary $(L)$, oil flow rate will not be affected by thermal effects with time passing and still keep at $q_{v}$. The limitation of heat conduction ability in a long enough combustion tube is responsible for this. Then, (2.17) can be rewritten as follows:

$$
q(t, L)=q_{v}
$$

A basic solution in the simplest case with local thermal equilibrium is given as a reference for the discussion of subsequent results, based on remarkably limited 
knowledge consisting of very global balance arguments and disregarding all the details of the mechanisms in the reaction zone. Then, the local governing equations are formulated in a dimensionless form; (2.14) can be solved by defining the following parameters and dimensionless groups.

Let

$$
\begin{gathered}
q_{D}=\frac{q(t, x)-q_{v}}{q_{c}-q_{v}}, \\
x_{D}=\frac{\beta x}{\alpha}, \\
t_{D}=\frac{\beta^{2} t}{\alpha}, \\
C=\frac{\alpha \gamma}{\beta^{2}} .
\end{gathered}
$$

Finally, the expression of dimensionless oil flow rate ahead of burning front is

$$
\begin{aligned}
\frac{\partial q_{D}}{\partial t_{D}}= & \frac{\partial^{2} q_{D}}{\partial x_{D}{ }^{2}}-\frac{\left(q_{c}-q_{v}\right)}{q_{D}\left(q_{c}-q_{v}\right)+q_{v}}\left(\frac{\partial q_{D}}{\partial x_{D}}\right)^{2}+\frac{\partial q_{D}}{\partial x_{D}} \\
& +\frac{C\left[q_{D}\left(q_{c}-q_{v}\right)+q_{v}\right]}{\left(q_{c}-q_{v}\right)} \times \ln \frac{q_{v}}{q_{D}\left(q_{c}-q_{v}\right)+q_{v}}
\end{aligned}
$$

where $C$ is dimensionless heat loss constant; $q_{D}$ is the dimensionless oil flow rate; $x_{D}$ is the dimensionless distance; $L_{D}$ is the dimensionless combustion tube length; $t_{D}$ is the dimensionless time.

And then, the initial and boundary conditions can be presented as below:

$$
\begin{gathered}
q_{D}\left(0, x_{D}\right)=\frac{q_{v}-q_{v}}{q_{c}-q_{v}}=0, \\
q_{D}\left(t_{D}, 0\right)=\frac{q(t, 0)-q_{v}}{q_{c}-q_{v}}=\frac{q_{c}-q_{v}}{q_{c}-q_{v}}=1, \\
\lim _{x_{D} \rightarrow \infty} \frac{\partial q_{D}}{\partial x_{D}}\left(t_{D}, x_{D}\right)=0 .
\end{gathered}
$$

Similar scenario is that (2.23) becomes,

$$
q_{D}\left(t_{D}, L_{D}\right)=0
$$

It should be noted that $q_{D}=0$ means that a certain place is not swept by thermal effects and oil flow rate keeps constant at $q_{v}$. 


\section{Numerical Simulations}

\subsection{Discretization}

Penberthy and Ramey [17] gave an analytical solution for the heat conduction model. For the development of this model, other authors use analytical method [18-20]. In this paper, we solve the governing PDEs by finite difference method. Dimensionless oil flow rate $q_{D}$ in $1 \mathrm{D}$ combustion tube was modeled. The principle of this method is illustrated in Figure 2. For most field upscaling, combustion can be included in a limited fashion in simulations at the expense of extra computational time and complexity. A fine grid can capture the combustion front propagation $[14,29,30]$. In this study, a fine grid block in 1D simulations is employed. The combustion tube length $(L)$ is divided into I space intervals $\Delta x_{D}$. The time is divided into $J$ time intervals $\Delta t_{D}$ (for all of the simulations we have chosen: $I=100$ and $J=20000$; $\Delta x_{D}=0.01$ and $\Delta t_{D}=0.01$, therefore the total dimensionless length and dimensionless time are 1 and 200, resp.). Every approximate value of $q_{D}$ above $\left(t_{0}+j \Delta t_{D}\right)$ time axis can be independently calculated from the value in $t_{0}+(j-1) \Delta t_{D}$ time axis. More specifically, $q_{D}$ for a new time step $\left(t_{D}=t_{0}+\Delta t_{D}\right)$ can be calculated, when $q_{D}$ is known at the previous time step $\left(t_{D}=t_{0}\right) \cdot q_{D}$ at the outer grid points $(i=0 \mathrm{v} i=I \mathrm{v} j=0 \mathrm{v} j=J)$ for the new time step $\left(t_{D}=t_{0}+\Delta t_{D}\right)$ is calculated using the boundary conditions. At time $t_{D}=0, q_{D}$ is given by the initial condition; hence, $q_{D}$ at $t_{D}=0+\Delta t_{D}, t_{D}=0+2 \Delta t_{D}, t_{D}=0+3 \Delta t_{D} \cdots t_{D}=0+J \Delta t_{D}$ can be calculated sequentially.

The backward difference method is employed in this study. Discretization of (2.20) can be written as follows;

$$
\begin{aligned}
\frac{q_{D j}^{i}-q_{D j-1}^{i}}{\Delta t_{D}}= & \frac{q_{D j-1}^{i+1}-2 q_{D j-1}^{i}+q_{D j-1}^{i-1}}{\left(\Delta x_{D}\right)^{2}}-\frac{\left(q_{c}-q_{v}\right)}{q_{D j-1}^{i}\left(q_{c}-q_{v}\right)+q_{v}}\left(\frac{q_{D j-1}^{i}-q_{D j-1}^{i-1}}{\Delta x_{D}}\right)^{2} \\
& +\frac{q_{D j-1}^{i}-q_{D j-1}^{i-1}}{\Delta x_{D}}+\frac{C\left[q_{D j-1}^{i}\left(q_{c}-q_{v}\right)+q_{v}\right]}{\left(q_{c}-q_{v}\right)} \ln \frac{q_{v}}{q_{D j-1}^{i}\left(q_{c}-q_{v}\right)+q_{v}} .
\end{aligned}
$$

\subsection{Parameters Determination}

The dimensionless oil flow rate modeling and simulation require a fit to experiment data to determine model parameters. In this study, most of model parameters are according to Keke Ya reservoir conditions (Tarim oilfield, branch of CNPC), which are stated in previous studies $[11,12,31]$. The viscosity of crude oil under different temperature was measured using Brookfield viscometer DV-III. The viscosity versus temperature curve is shown in Figure 3. The experimental date can be perfectly exponential regressed with expression $\mu=4.70844 e^{-0.0094 T}$. Hence, the values of $\mu_{v}$ and $\mu_{c}$ are obtained. This study has different types of parameters as shown in Table 1 .

\section{Results and Discussion}

Several variables can affect the oil flow rate contributed by thermal effects. In this section, the influences of two main variables $\left(t_{D}, x_{D}\right)$ on oil flow rate and resulting guidelines will be studied. It should be noted that no systematic experimental results of process variation were 


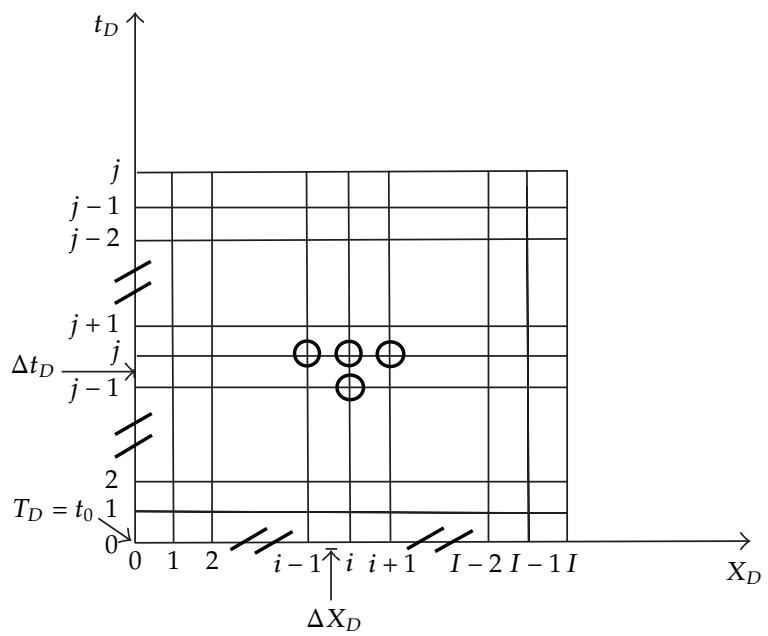

Figure 2: Representation of grid blocks used in the simulation: calculation of the $q_{D}$ at a new time step from the $q_{D}$ at the previous time step.

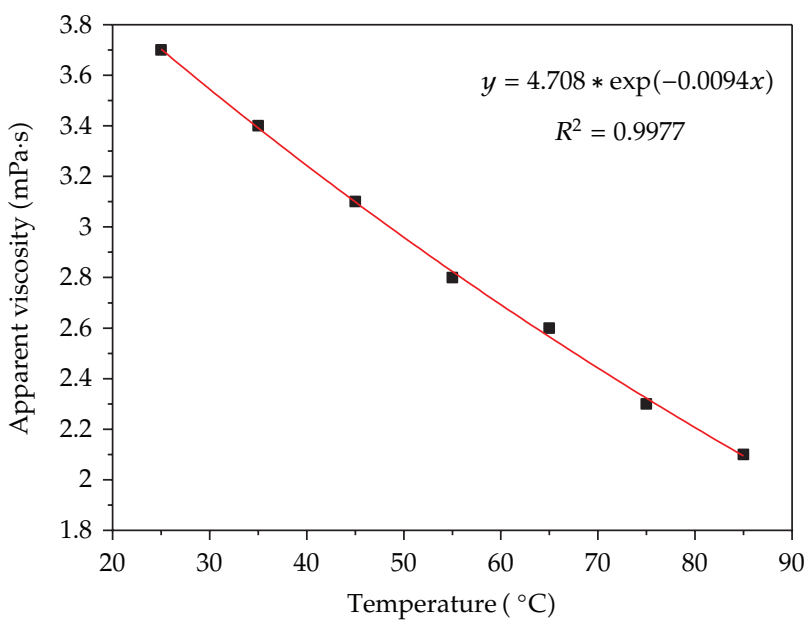

- Experimental data

- Fitted line

Figure 3: The evolution of oil viscosity at different temperatures.

Table 1: Model parameters and properties.

\begin{tabular}{lccc}
\hline$\mu_{v}$ & $2.213 \mathrm{mPa} \cdot \mathrm{s}$ & $L$ & $1000 \mathrm{~cm}$ \\
$\mu_{c}$ & $1.139 \mathrm{mPa} \cdot \mathrm{s}$ & $T_{v}$ & $80^{\circ} \mathrm{C}$ \\
$\rho_{o}$ & $805 \mathrm{~kg} / \mathrm{m}^{3}$ & $T_{c}$ & $150^{\circ} \mathrm{C}$ \\
$g$ & $9.8 \mathrm{~m} / \mathrm{s}^{2}$ & $C$ & 0.5 \\
$K_{o}$ & $0.2 \mu \mathrm{m}^{2}$ & $G$ & $500 \mathrm{~Pa} / \mathrm{cm}$ \\
$\Delta P$ & $5 \times 10^{5} \mathrm{~Pa}$ & $q_{v}$ & $0.089 \mathrm{~cm}^{3} / \mathrm{s}$ \\
$r_{t}$ & $2.5 \mathrm{~cm}$ & $q_{c}$ & $0.172 \mathrm{~cm}^{3} / \mathrm{s}$ \\
\hline
\end{tabular}

Note: $G, q_{v}$, and $q_{c}$ are calculated from the above parameters. 
available for the oil flow rate of this study. Hence, simulation results will be used to quantify trends caused by process variations. Systematical experimental studies will be conducted in comparison with the predicted trend in the forthcoming paper.

\subsection{Effect of $t_{D}$}

Figure 4 shows the profiles of the relationships of $q_{D}$ in different $x_{D}(0,0.01,0.03,0.05$, and 0.07 , shown in the legend) with the increasing of $t_{D}$. For $x_{D}=0, q_{D}$ has the maximum value of 1.0; it indicates that the formed peak temperaure $T_{c}$ in the initial space can provide the steady highest oil flow ability. In the space adjacent to $T_{c}$ (i.e., $x_{D}=0.01$ ), $q_{D}$ initially shows linear increasing characteristic with high positive slopes $\left(d q_{D} / d t_{D}>0\right)$, and the slope value sharply increases to 0.4 in less than $t_{D}=4$, and then followed by a smooth increasing stage until to a plateau. The final $q_{D}$ value is around 0.95 which is slight below the highest oil flow rate value of 1.0 at the initial place $\left(x_{D}=0\right)$. It reflects the temperature profiles ahead of combustion front have smooth characteristic. Several studies also demonstrated that temperature profiles both from simulation run or laboratory experiments will show the same law of smooth turning to a plateau after the peak temerature [32].

The simulation result reveals that the closest space to $T_{c}$ can provide high oil flow rate in a short time. because high temperature can reduce oil viscosity to a high extent for its better mobilization. The high positive slope in the earlier stage means that temperature in $x_{D}=0.01$ rapidly elevates to maximum value due to the propagation of combustion front from the initial place; when the steady combustion front formed, oil mobilization ability will become constant and show around 0.95 in later period from $t_{D}=160$ to 200. For $x_{D}=0.03,0.05,0.07$, the corresponding curves show the similar trend as the former $x_{D}=0.01$. Most importantly, the three curves have three important characteristics: (1) a $q_{D}=0$ period was found and delayed with the increasing of $x_{D}$; (2) the positive slopes in the early stage are apparently decreased with the increasing of $x_{D}$; (3) the smooth increasing period of $q_{D}$ has been largely extended in this given total time interval.

The specified " $q_{D}=0$ period" means that oil flow rate is at the original level and is not affected by the thermal effects. The relative far dimensionless distance shows a longer $q_{D}=0$ period; for instance, in $x_{D}=0.03,0.05,0.07$, the $q_{D}=0$ periods are around $t_{D}=0.5,2,3$, respectively.

Furthermore, $q_{D}$ at terminating time $t_{D}=200$ shows greater difference in each $x_{D}$ interval. Compared to the value of 0.95 at $x_{D}=0.01$ at $t_{D}=200, q_{D}$ in the other three $x_{D}$ intervals reduces to $0.84,0.74$, and 0.65 , respectively. In addition, we found that $q_{D}$ decreasing gradient is nearly the same for the same $x_{D}$ intervals (i.e., the $D$ value of $q_{D}$ keeps at around 0.1 for the same space interval increments of $0.02 \Delta x_{D}$ ). It denotes that temperature in each place along the combustion tube will become constant with the increasing of time. Hence, smooth $q_{D}$ curves can be detected due to the stable lowered oil viscosity. However, $q_{D}$ decreasing gradient at the same $t_{D}$ does not show the same value in the early stage as obviously illustrated by the arrowheads. The discrepancy may be ascribed to the sharply decreasing of temperature in the relative high temperature $\left(T_{c}\right)$ approached zone. For instance, a rapid temperature decreasing followed by a smooth temperature decreasing tendency is often observed in combustion tube experiments.

Figure 5 shows that a longer $q_{D}=0$ period widely exists in further distances and also prolongs with increasing of distance. For $x_{D}=0.15$ to 0.45 , the $q_{D}=0$ period ranges from $t_{D}=9$ to 65 . However, in $x_{D}=0.60, q_{D}$ values are kept constant at zero for all the time. 


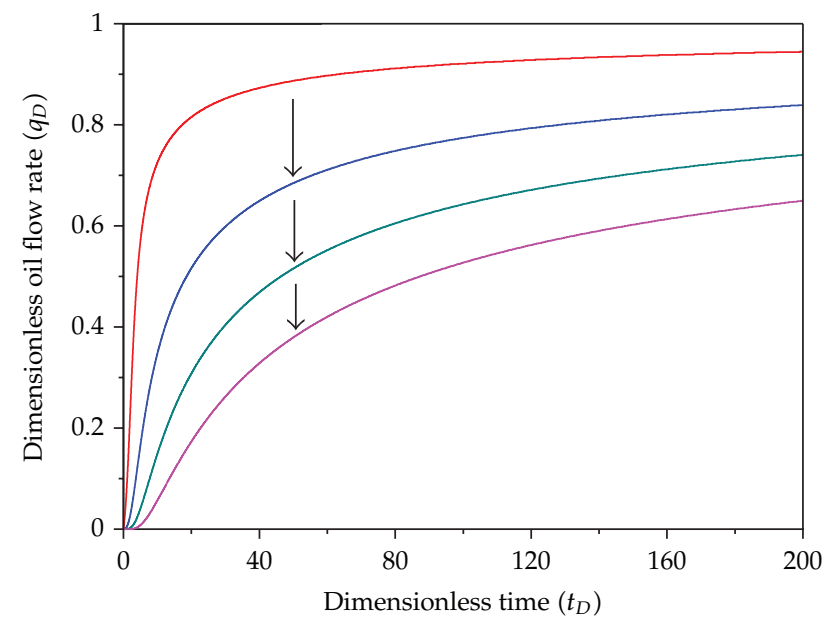

(a)

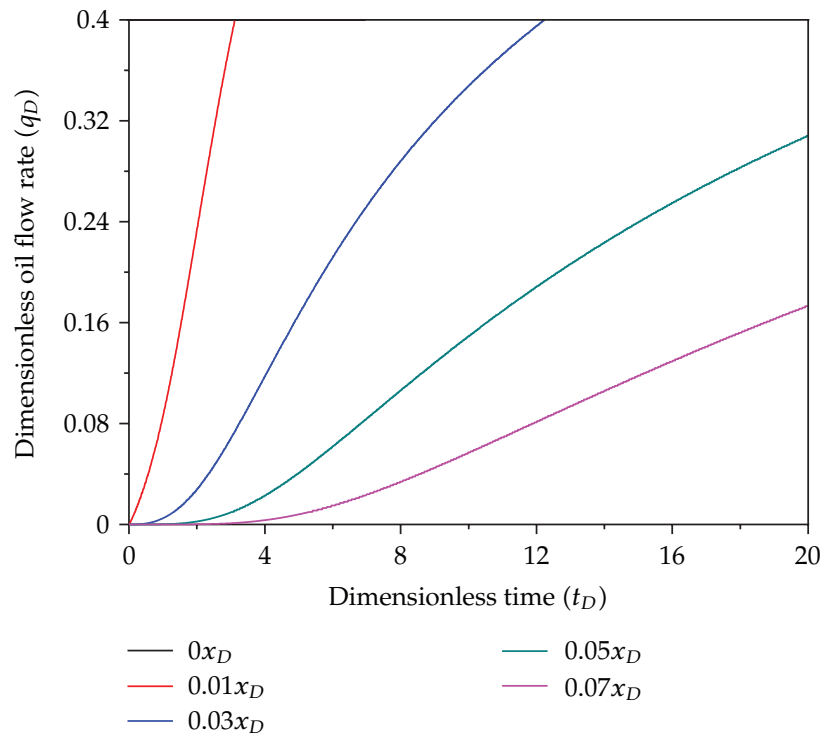

(b)

Figure 4: Results from dynamic simulation of the relationship of $q_{D}$ versus $t_{D}$ in different $x_{D}$ (The selected $x_{D}$ is approach to the upper limit temperature).

It implies that the dimensionless distance is not affected by the combustion front and oil is mobilized only under the initial oil viscosity at reservoir temperature. On the other hand, the endpoint values of the curve clusters are sharply decreased compared to the distance approach to the upper limit temperature, it reveals that the ability of thermal effects on oil flow rate is restricted in a short distance.

For a far distance, temperature gradually tends to reservoir temperature, which corresponde to the illustration in Figure 1. And hence, thermal effects cannot efficiently sweep in this area. For heavy oil reservoirs, crude oil located at a far distance could be swept by thermal effects because a slight temperature increasing can efficiently reduce oil 


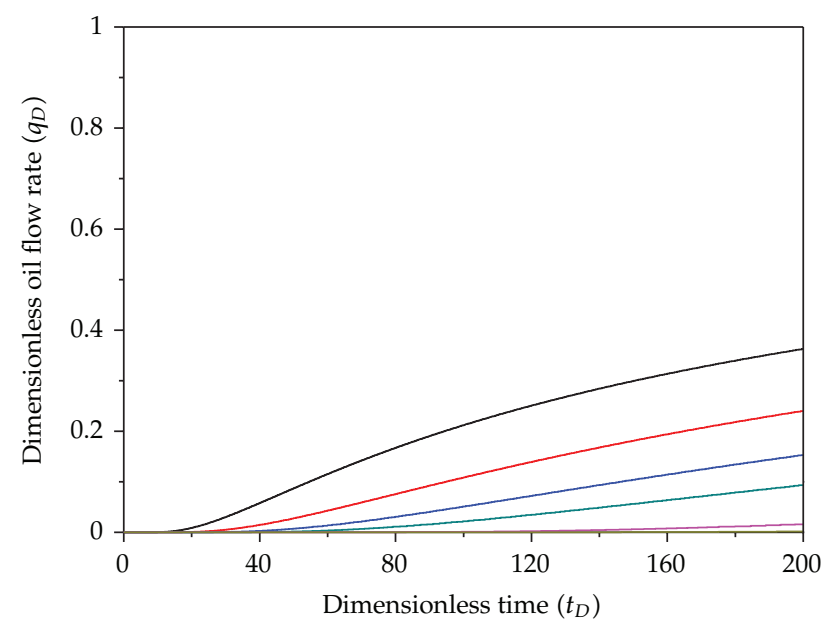

(a)

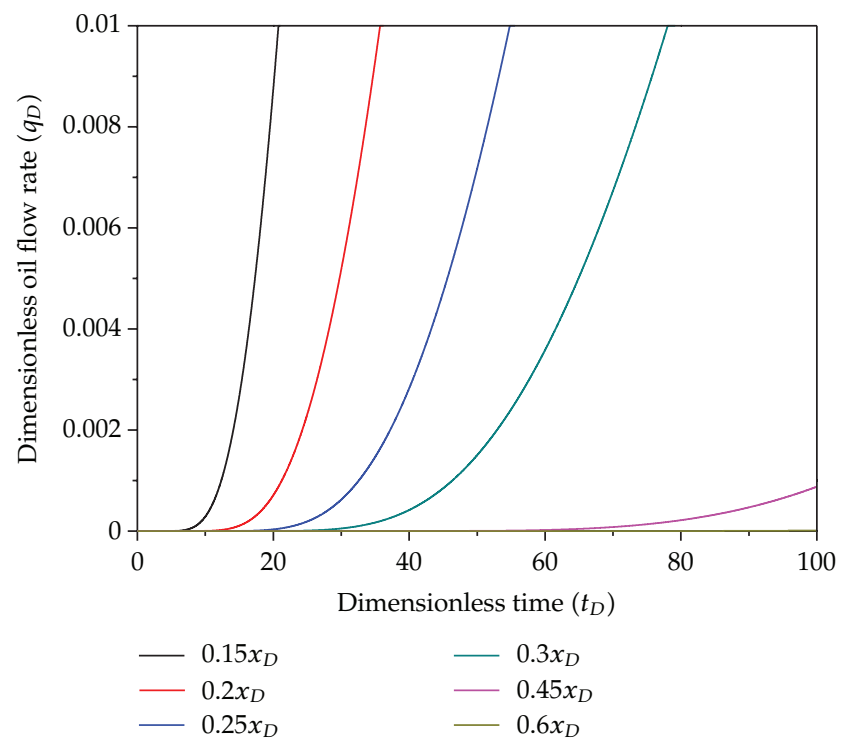

(b)

Figure 5: Results from dynamic simulation of the relationship of $q_{D}$ versus $t_{D}$ in different $x_{D}$ (The selected $x_{D}$ is far away from the upper limit temperature).

viscosity for improving oil production. But it is not the same case for light oil reservoirs due to the nature of low viscosity of light crude oil because the decreasing amplitude degree of light crude oil viscosity is rather limited. The rapid $q_{D}$ decreasing also relates to the thin combustion front $[13,23]$. The available literature has shown that a combustion front inside a porous medium could have a length of 2 to $5 \mathrm{~mm}$ [33].

A smooth increasing trend is obviously detected for all the curves. However, these curves will not unlimitedly increase and are bound to reach a plateau with low $q_{D}$ values as time passes. On the other hand, it seems that high oil flow rate can be achieved by extending production time in an HPAI process. It is proposed that extending air injection project cycle 
is desired to achieve high ultimate oil recovery. Nevertheless, all the results are based on the assumption that combustion front is steady propagating that can sweep to any far distance provided that injection time is infinite. However, in actual reservoirs, the combustion front may not favourably propagate because of the complex lithology and liquid properties under reservoir conditions.

\subsection{Effect of $x_{D}$}

$q_{D}$ profiles as a function of $x_{D}$ are shown in Figure 6. $q_{D}$ distribution curves varied in different $t_{D}\left(t_{D}=0,20,60,100\right.$, and 200, shown in the legend $)$ and all curves show the similar decreasing trend with the increase of $x_{D}$. The horizontal line used for comparison shows that in initial time oil flow rate has not been affected by thermal effects in any place of the combustion tube. When combustion front formed, $q_{D}$ shows the maximum value 1.0 all the time in the initial place. In the earlier stage, $q_{D}$ profiles display a high negative slope $\left(\mathrm{d} q_{D} / \mathrm{d} x_{D}<0\right)$ and sharply decrease along the combustion tube, and then followed by a smooth decreasing in a very short distance until they become zero. For instance, $q_{D}$ profile in $t_{D}=20$ depicts a high oil flow rate decline stage and the influences of thermal effects on oil flow rate are only restricted within $x_{D}=0.2$. It means that oil flow rate in subsequent distance is not affected by thermal effects. However, oil flow decreasing rate is mitigated with the increasing of dimensionless time. The swept distances done by thermal effects are $x_{D}=0.2,0.3,0.4$ and 0.6 at $t_{D}=20,60,100$ and 200, respectively. It indicates that a longer time is needed for heat conduction to a far distance when combustion front velocity $v_{b}$ keeps constant. In $t_{D}=200$, a long transitional period exists in $q_{D}$ profile; we can see that a decline stage apparently shows from $x_{D}=0.4$ to 0.6 , which is much longer than the earlier stage. It gives us an important enlightenment that oil production contributed by thermal effects can be enhanced through reducing well spacing or extending air injection cycle. That is to say, for $100 \mathrm{~m}\left(x_{D}=0.1\right)$ well spacing test wells can achieve more oil production than that of $200 \mathrm{~m}$ $\left(x_{D}=0.2\right)$ well spacing test wells whilst air injection cycle is the same.

It should be noted that increasing air injection cycle can maintain the successive combustion front and heat conduction ability, because a stable-persistent combustion front strongly relies on the addition of enough oxygen [5]. But it will increase the extra operation cost.

\section{Conclusions}

We show how to derive mathematical models for studying the space-time distributions of oil flow rate caused by thermal effects and the finite difference method is employed to solve the governing equations. The theory of "thermal effects" is described by the previous discussion and reveals that the role of combustion front seems like a bulldozer to move the oil ahead of it, and the very adjacent place to the combustion front (upper limit temperature) can provide high oil flow rate, whereas a far distance will be swept by thermal effects provided time increases. Sensitive analysis on oil flow rate proposes that such methods as reducing well spacing and extending air injection cycle shoud be taken into consideration to achieve high cumulative oil production contributed by thermal effects, and further studies should be addressed to reappraise its contribution to oil production by way of quantitative analysis. The influences of thermal effects on oil production should not be treated as an episode. Our findings may give a new avenue for the study of thermal effects on oil production in HPAI 


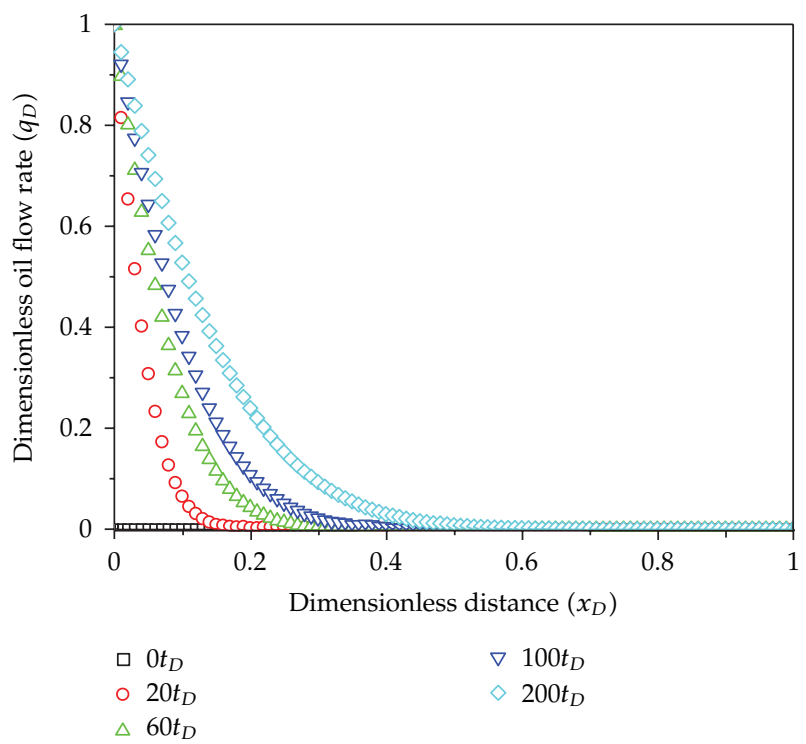

Figure 6: Results from dynamic simulation of the relationship of $q_{D}$ distribution in $x_{D}$.

process in light oil reservoirs. However, there is still a lot of work that should be loaded, because the combustion process is very complex. We hope that the results of our analysis encourage such investigations.

\section{Acknowledgments}

This work was financially supported by the Key Technologies Research and Development Program of China (2011ZX05049-004-004-008), Sichuan Provincial Youth Science and Technology Fund (2012JQ0010), Program for New Century Excellent Talents in University (NCET-11-1062), and the National "Top100 Doctoral Dissertation" Cultivation Fund of the Southwest Petroleum University to Hu Jia. The authors express their sincere appreciation to technical reviewers for their constructive comments.

\section{References}

[1] M. R. Fassihi, D. V. Yannimaras, E. E. Westfall, and T. H. Gillham, “Economics of light oil air injection projects," in Proceedings of the 10th Symposium on Improved Oil Recovery SPE/DOE, paper 35393, pp. 501-509, Tulsa, Okla, USA, April 1996.

[2] T. H. Gillham, B. W. Cerveny, E. A. Turek, and D. V. Yannimaras, "Keys to increasing production via air injection in Gulf Coast light oil reservoirs," in Proceedings of the SPE Annual Technical Conference and Exhibition, paper 38848, pp. 65-80, San Antonio, Tex, USA, October 1997.

[3] B. Niu, S. Ren, Y. Liu, D. Wang, L. Tang, and B. Chen, "Low-temperature oxidation of oil components in an air injection process for improved oil recovery," Energy E Fuels, vol. 25, no. 10, pp. 4299-4304, 2011.

[4] V. Alvarado and E. Manrique, "Enhanced oil recovery: an update review," Energies, vol. 3, no. 9, pp. 1529-1575, 2010.

[5] A. R. Montes, R. G. Moore, S. A. Mehta, M. G. Ursenbach, and D. Gutiérrez, "Is high-pressure air injection (HPAI) simply a flue-gas flood?" Journal of Canadian Petroleum Technology, vol. 49, no. 2, pp. 56-63, 2010. 
[6] S. Sakthikumar, K. Madaoui, and J. Chastang, "An investigation of the feasibility of air injection into a waterflooded light oil reservoir," in Proceedings of the SPE Middle East Oil Show, paper 29806, pp. 343-356, Bahrain ,Bahrain, March 1995.

[7] C. A. Glandt, R. Pieterson, A. Dombrowski, and M. A. Balzarini, "Coral creek field study: a comprehensive assessment of the potential of high-pressure air injection in a mature waterflood project," in Proceedings of the SPE Mid-Continent Operations Symposium, paper 52198, Oklahoma, Okla, USA, March 1999.

[8] D. Gutierrez, R. G. Moore, S. A. Mehta, M. G. Ursenbach, and F. Skoreyko, "The challenge of predicting field performance of air injection projects based on laboratory and numerical modeling," Journal of Canadian Petroleum Technology, vol. 48, no. 4, pp. 23-33, 2009.

[9] D. Gutiérrez, A. R. Taylor, V. K. Kumar, M. G. Ursenbach, R. G. Moore, and S. A. Mehta, "Recovery factors in high-pressure air injection project revisited," SPE Reservoir Evaluation E Engineering, vol. 11, no. 6, pp. 1097-1106, 2008.

[10] O. S. Shokoya, Enhanced recovery of conventional crude oils with flue gas [Doctoral dissertation], University of Calgary, 2005.

[11] H. Jia, J. Z. Zhao, W. F. Pu, R. Liao, and L. L. Wang, "The influence of clay minerals types on the oxidation thermokinetics of crude oil," Energy Sources A, vol. 34, no. 10, pp. 877-886, 2012.

[12] H. Jia, J. Z. Zhao, W. F. Pu, J. Zhao, and X. Y. Kuang, "Thermal study on light crude oil for application of high-pressure air injection (HPAI) process by TG/DTG and DTA tests," Energy E Fuels, vol. 26, no. 3, pp. 1575-1584, 2012.

[13] H. K. Sarma and S. Das, "Air injection potential in Kenmore oilfield in Eromanga Basin, Australia: a screening study through thermogravimetric and calorimetric analyses," in Proceedings of the 16th SPE Middle East Oil and Gas Show and Conference (MEOS '09), paper 120595, Bahrain, Bahrain, March 2009.

[14] A. M. de Zwart, D. W. van Batenburg, C. P. A. Blom, A. Tsolakidis, C. A. Glandt, and P. Boerrigter, "The modeling challenge of high-pressure air injection," in Proceedings of the 16th SPE/DOE Improved Oil Recovery Symposium, paper 113917, pp. 1204-1216, Tulsa, Okla, USA, April 2008.

[15] G. Debenest, V. V. Mourzenko, and J.-F. Thovert, "Smouldering in fixed beds of oil shale grains: governing parameters and global regimes," Combustion Theory and Modelling, vol. 9, no. 2, pp. 301-321, 2005.

[16] S. R. Ren, M. Greaves, and R. R. Rathbone, "Air injection LTO process: an IOR technique for light-oil reservoirs," SPE Journal, vol. 7, no. 1, pp. 90-99, 2002.

[17] W. L. Penberthy and H. J. Ramey, "Design and operation of laboratory combustion tube," SPE Journal, vol. 6, no. 2, pp. 183-198, 1966.

[18] J. R. Rodriguez, Experimental and analytical study to model temperature profiles and stoichiometry in oxygenenriched in-situ combustion [Doctoral dissertation], Texas A\&M University, College Station, 2004.

[19] J. R. Rodriguez and D. D. Mamora, "Analytical model of the combustion zone in oxygen-enriched in-situ combustion tube experiments," in Proceedings of the Canadian International Petroleum Conference, paper 2005-072, Alberta, Canada, June 2005.

[20] H. Jabbari, R. Kharrat, Z. Zeng, V. Mostafavi, and A. Emamzadeh, "Modeling the toe-to-heel air injection process by introducing a new method of type-curve match," in Proceedings of the SPE Western Regional Meeting, paper 132515, pp. 282-295, Anaheim, Calif, USA, May 2010.

[21] A. P. Aldushin, I. E. Rumanov, and B. J. Matkowsky, "Maximal energy accumulation in a superadiabatic filtration combustion wave," Combustion and Flame, vol. 118, no. 1-2, pp. 76-90, 1999.

[22] M. F. Martins, S. Salvador, J.-F. Thovert, and G. Debenest, "Co-current combustion of oil shale-part 1: characterization of the solid and gaseous products," Fuel, vol. 89, no. 1, pp. 144-151, 2010.

[23] B. L. Hughes and H. K. Sarma, "Burning reserves for greater recovery? Air injection potential in Australian light oil reservoirs," in Proceedings of the SPE Asia Pacific Oil E Gas Conference and Exhibition, paper 101099, pp. 637-653, Adelaide, Australia, September 2006.

[24] H. K. Sarma, N. Yazawa, R. G. Moore et al., "Screening of three light-oil reservoirs for application of air injection process by accelerating rate calorimetric and TG/PDSC tests," Journal of Canadian Petroleum Technology, vol. 41, no. 3, pp. 50-60, 2002.

[25] H. B. Al-Saffar, H. Hasanin, D. Price, and R. Hughes, "Oxidation reactions of a light crude oil and its SARA fractions in consolidated cores," Energy \& Fuels, vol. 15, no. 1, pp. 182-188, 2001.

[26] C. Clara, M. Durandeau, G. Quenault, and T. H. Nguyen, "Laboratory studies for light oil air injection projects: potential application in Handil field," in Proceedings of the SPE Asia Pacific Oil $\mathcal{E}$ Gas Conference and Exhibition, paper 54377, Jakarta, Indonesia, April 1999. 
[27] R. G. Moore, S. A. Mehta, and M. G. Ursenbach, “A guide to high pressure air injection (HPAI) based oil recovery," in Proceedings of the SPE/DOE Improved Oil Recovery Symposium, paper 75207, Tulsa, Okla, USA, April 2002.

[28] M. Kumar, "Simulation of laboratory in-situ combustion data and effect of process variations," in Proceedings of the 9th SPE Symposium on Reservoir Simulation, paper 16027, San Antonio, Tex, US, February 1987.

[29] P. H. Sammon, "Dynimaic grid refinement and amalgmation for compositional simulation," in Proceedings of the SPE Reservoir Simulation Symposium, paper 79683, Houston, Tex, USA, February 2003.

[30] D. W. van Batenburg, M. Bosch, P. M. Boerrigter, A. H. de Zwart, and J. C. Vink, "Application of dynamic gridding techniques to IOR/EOR-processes," in Proceedings of the SPE Reservoir Simulation Symposium, paper 141711, The Woodlands, Tex, USA, February 2011.

[31] H. Jia, J. Z. Zhao, W. F. Pu, Y. M. Li, Z. T. Yuan, and C. D. Yuan, "Laboratory investigation on the feasibility of light-oil autoignition for application of the high-pressure air injection (HPAI) process," Energy \& Fuels, vol. 26, no. 9, pp. 5638-5645, 2012.

[32] B. E. Dembla Dhiraj, Simulating enhanced oil recovery (EOR) by high-pressure air injection (HPAI) in West Texas light oil reservoir [M.S. thesis], The University of Texas at Austin, 2004.

[33] G. Debenest, V. V. Mourzenko, and J.-F. Thovert, "Three-dimensional microscale numerical simulation of smoldering process in heterogeneous porous media," Combustion Science and Technology, vol. 180, no. 12 , pp. 2170-2185, 2008. 


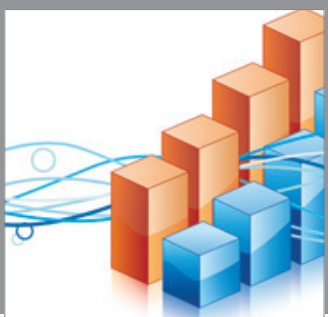

Advances in

Operations Research

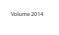

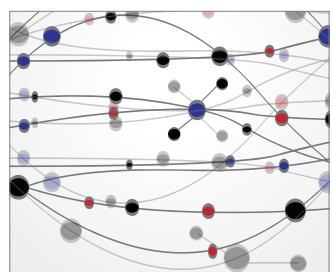

\section{The Scientific} World Journal
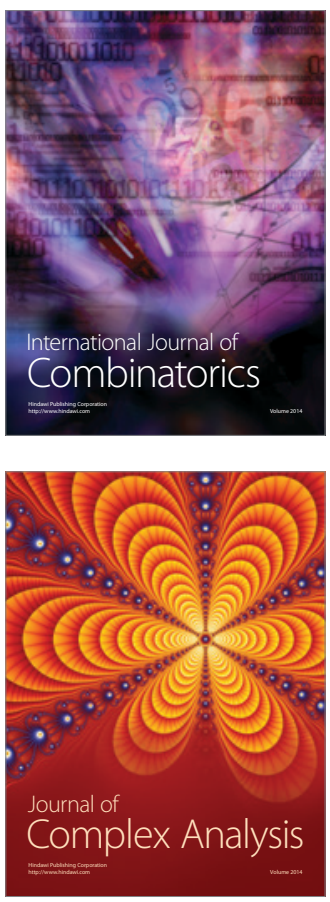

International Journal of

Mathematics and

Mathematical

Sciences
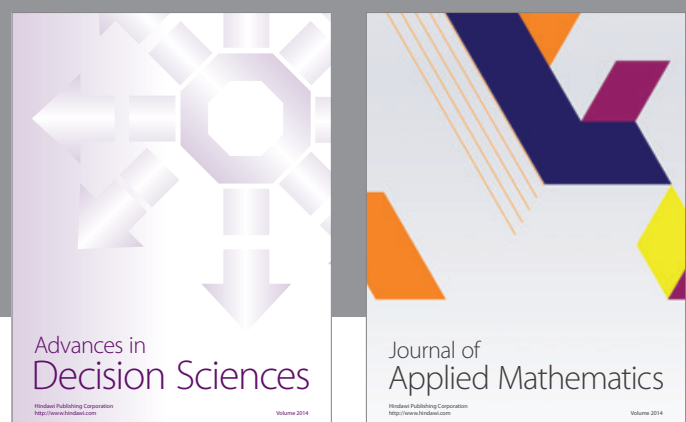

Journal of

Applied Mathematics
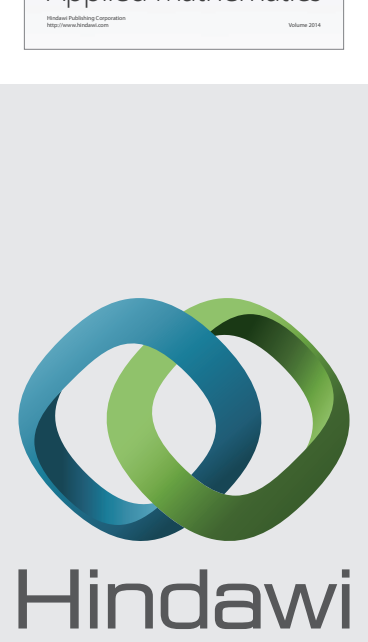

Submit your manuscripts at http://www.hindawi.com
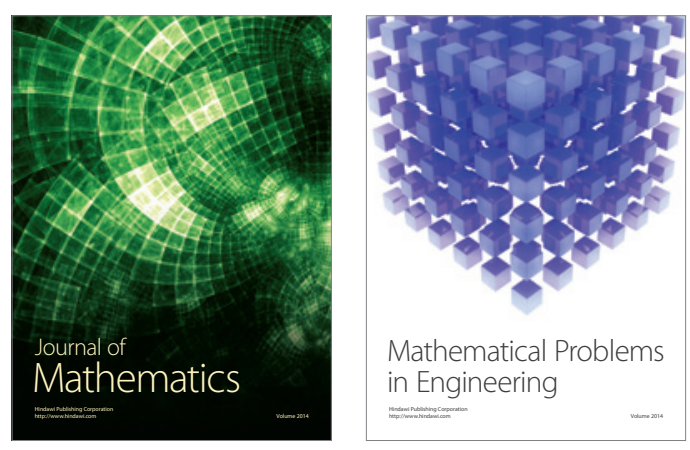

Mathematical Problems in Engineering
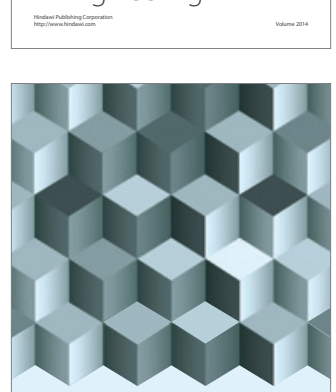

Journal of

Function Spaces
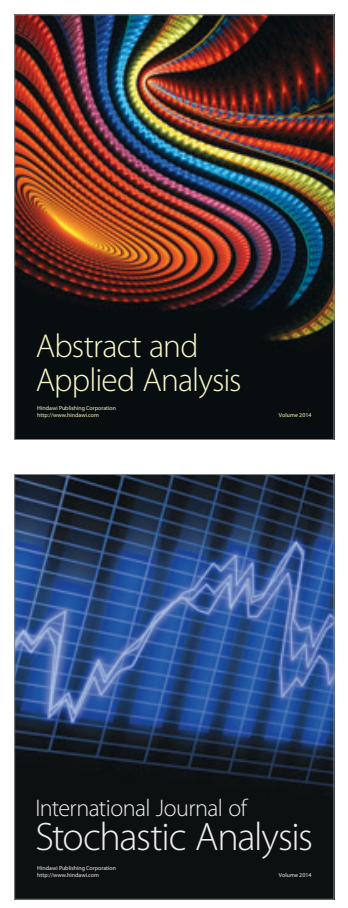

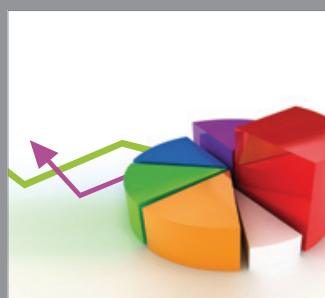

ournal of

Probability and Statistics

Promensencen
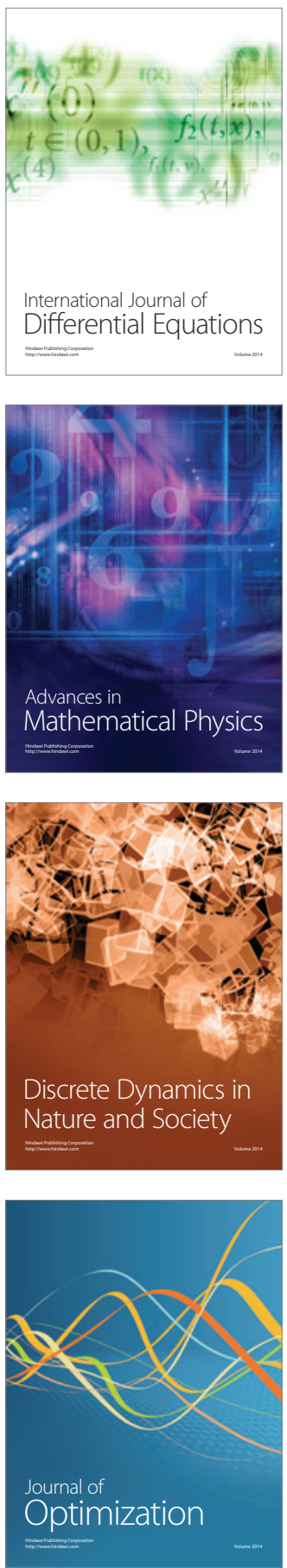